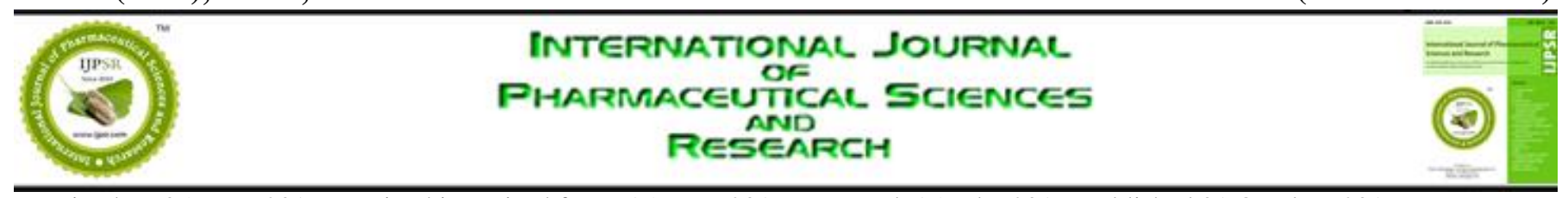

Received on 05 May, 2016; received in revised form, 15 June, 2016; accepted, 15 July, 2016; published 01 October, 2016

\title{
COMPARATIVE MODELING OF INACTIVE UBIQUITIN THIOESTERASE FAM105A AND MOLECULAR DOCKING STUDIES OF SYNTHESIZED BENZIMIDAZOLE DERIVATIVES
}

\author{
M. Neelamma ${ }^{* 1}$ and Kiran Kumar Chitluri ${ }^{2}$
}

University College of Science ${ }^{1}$, Saifabad, Osmania University, Hyderabad, Telangana, India.

Bioinformatics Division ${ }^{2}$, Osmania University, Hyderabad - 500007, Telangana, India.

Keywords:

Benzimidazole, Homology modeling, Modeller9.15, Molecular docking studies, Procheck.

\section{Correspondence to Author:}

M. Neelamma

University College of Science, Saifabad, Osmania University, Hyderabad, Telangana, India.

Email:nbudarapu@gmail.com

\begin{abstract}
In this study, homology modeling and molecular docking studies were performed to explore structural features and binding mechanism of synthesized benzimidazole derivatives as ubiquitin inhibitors. A homology modeling procedure was employed to construct a 3D model of ubiquitin protein by using MODELLER9.15. For this procedure, the X-ray crystal structure of Gumby / fam 105b in Complex with linear Di-ubiquitin (PDB ID: 4KSL) at $2.83 \AA$ resolution was used as template. The predicted model was analyzed by PROCHECK. The 3D structure of predicted model shows $93.9 \%$ of amino acids in most favored region. The predicted model was used for molecular docking studies by using Autodock4.2. All the synthesized benzimidazole derivatives show good binding energy and interactions with the model. Compound one shows three interactions with Asp348, Leu297 and Tyr351.
\end{abstract}

INTRODUCTION: Ubiquitination is the process of classifying a target protein with ubiquitin. ${ }^{1}$ The process of ubiquitination is mediated by three enzymes 1. ubiquitin activating enzyme (E1), 2. ubiquitin conjugating enzyme (E2) and 3. ubiquitin ligase (E3).The most important function of E1 ubiquitin activating enzyme is to catalyze the adenylation of ubiquitin at the expense of one ATP molecule. ${ }^{2}$ Ubiquitination play an important role in cellular process, which include cell-cycle progression, endocytosis and trafficking, and immune-signal transduction. ${ }^{3}$

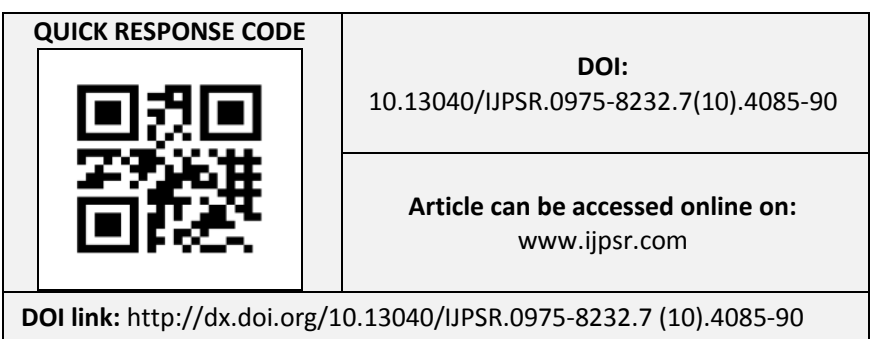

Activation enzyme of Ubiquitin E1 activates the 76-amino acid residue ubiquitin polypeptide by forming a thioester bond. The thioester bond forms in between its catalytic cysteine and the $\mathrm{C}$ terminus of ubiquitin in an ATP-dependent manner. Through a transthiolation reaction ubiquitin is transferred to the activate site cysteine in ubiquitinconjugating enzyme E2. In eukaryotes it is highly conserved but absent in bacteria. In the fused heterocyclic moieties benzimidazole nucleus plays an important pharmacophore with unique chemical and biological properties. ${ }^{5-8}$ They have been found to possess various biological activities like analgesic, antihistaminic, anti-inflammatory, antispasmodic, analgesic, antimicrobial, antitumor, antiproliferative, anti-HIV-RT, antiulcer, antitubercular, anti-cancer and anti-fungal ${ }^{9-12}$ antiinflammatory ${ }^{13}$, proton pump inhibitors ${ }^{14,15}$ and cycloxygenase inhibitor activities. ${ }^{16-20}$ Some of the benzimidazole derivatives are involved in 
medicinal treatment such as infertility, epilepsy and diabetic deseases. $^{21,22}$

In the present study, MODELLER9.15 was used to generate 3D model of Inactive ubiquitin thioesterase FAM105A (uniprot accession number: Q9NUU6) protein from human. Gumby/fam105b in Complex with linear Di-ubiquitin (PDB ID: 4KSL), is used as a template for model build up. Validation of model was performed by PROCHECK program. Active site prediction was performed by using 3D ligandsite, an online active site prediction tool and molecular docking study was performed using AutoDock4.2.

\section{Experimental data:}

\section{Sequence alignment and structure prediction:}

The amino acid sequence of Homosapiens Inactive ubiquitin thioesterase FAM105A (Accession No.Q9NUU6) was retrieved from the Uni Prot KB database (http://www.uniprot.org/) ${ }^{23}$. A BLAST ${ }^{24}$ (Basic Local Alignment Search Tool) search was performed to select the template and resulted with the best match Crystal Structure of Gumby/fam105b In Complex With Linear Diubiquitin (PDB ID: 4KSL (Chain A)) (http://blast.ncbi.nlm.nih.gov/Blast.cgi) with $41 \%$ similarity having a resolution of $2.83 \AA$ making it an excellent template. The three dimensional structure was generated using Modeller 9.15 ${ }^{25}$. The final validation of the model was performed using PROCHECK for Ramachandran plot. The RMSD (root mean square deviation) was calculated by superimposing (4KSL) over the generated model to access the accuracy and reliability of the generated model using SPDBV ${ }^{26}$ by selecting the main chain atom (i.e. the backbone atoms of alpha carbon).

MODELLER 9.15 was then used to gain satisfactory models; an automated approach to homology modeling by satisfaction of spatial restrains ${ }^{27}$. Initially, both the query and template were aligned by using clustal X. After manually modifying the alignment input file in MODELLER 9.15 to match the query and template sequence, 20 models were generated. After generating files least modeler objective function value containing PDB was selected to validate the model. These models were then checked in detail for the protein structure stereochemistry by using PROCHECK ${ }^{28}$, which generates Ramachandran plot and comprehensive residue by residue listing facilitates, the in depth assessment of Psi/Phi angles and the backbone conformation of the models.

\section{Docking protocol:}

The five synthesized Benzimidazole derivatives were sketched in sybyl6.7 and saved it into .mol2 format. Then the molecules were minimized using Tripos force field, Gasteiger-Huckel charges were added and used convergence criterion of 0.005 $\mathrm{kcal} / \mathrm{mol} \AA$. Molecular Docking study was performed to all the synthesized molecules separately by using AutoDock4.2 program, using the Lamarckian Genetic Algorithm (LGA) and implemented empirical free energy function. ${ }^{29}$ Initially, the modelled protein was loaded and polar hydrogen were added. The molecule was loaded and set conformations and saved it in PDBQT format and then saved generated PDB file to PDBQT format. The grid maps were selected and calculated using AutoGrid. ${ }^{30}$ For all dockings, a grid map with $60 \times 60 \times 60$ points and also used a grid-point spacing of $0.375 \AA$ was applied. Coordinates of $\mathrm{x}, \mathrm{y}, \mathrm{z}$ was set as $-42.267,33.699$, and 12.982 respectively. For all docking parameters, default values were used.

\section{RESULTS AND DISCUSSION:}

\section{Homology modelling and model evaluation:}

The present study reports that the template protein (PDB ID: 4KSL) having high degree of homology with Q9NUU6 protein was used as a template with good atomic resolution of its crystal structure. The target sequence of Inactive ubiquitin thioesterase FAM105A having 356 amino acid residues was retrieved from the uniprot protein sequence database with Accession No. Q9NUU6. PDB Id-4KSL was identified and selected as template using BLAST having $41 \%$ identity. The structure was modelled using modeller 9.15. The generated structure was validated using Protein Structure and by PROCHECK. The model show 93.9\% of amino acid residues in core region, $5.5 \%$ of amino acid residues in additionally allowed region, $0.6 \%$ of amino acid residues in generously favored region. There is no amino acid present in disallowed region. Both target and template molecules show nearly same amino acid residues in 
most favored region that is query sequence shows $93.7 \%$ in most favored region and template molecule contains $93.7 \%$ in most favored region.
Ramachandran plot and Secondary structure of the modelled protein is shown in Fig.1 and Fig. 2 respectively.

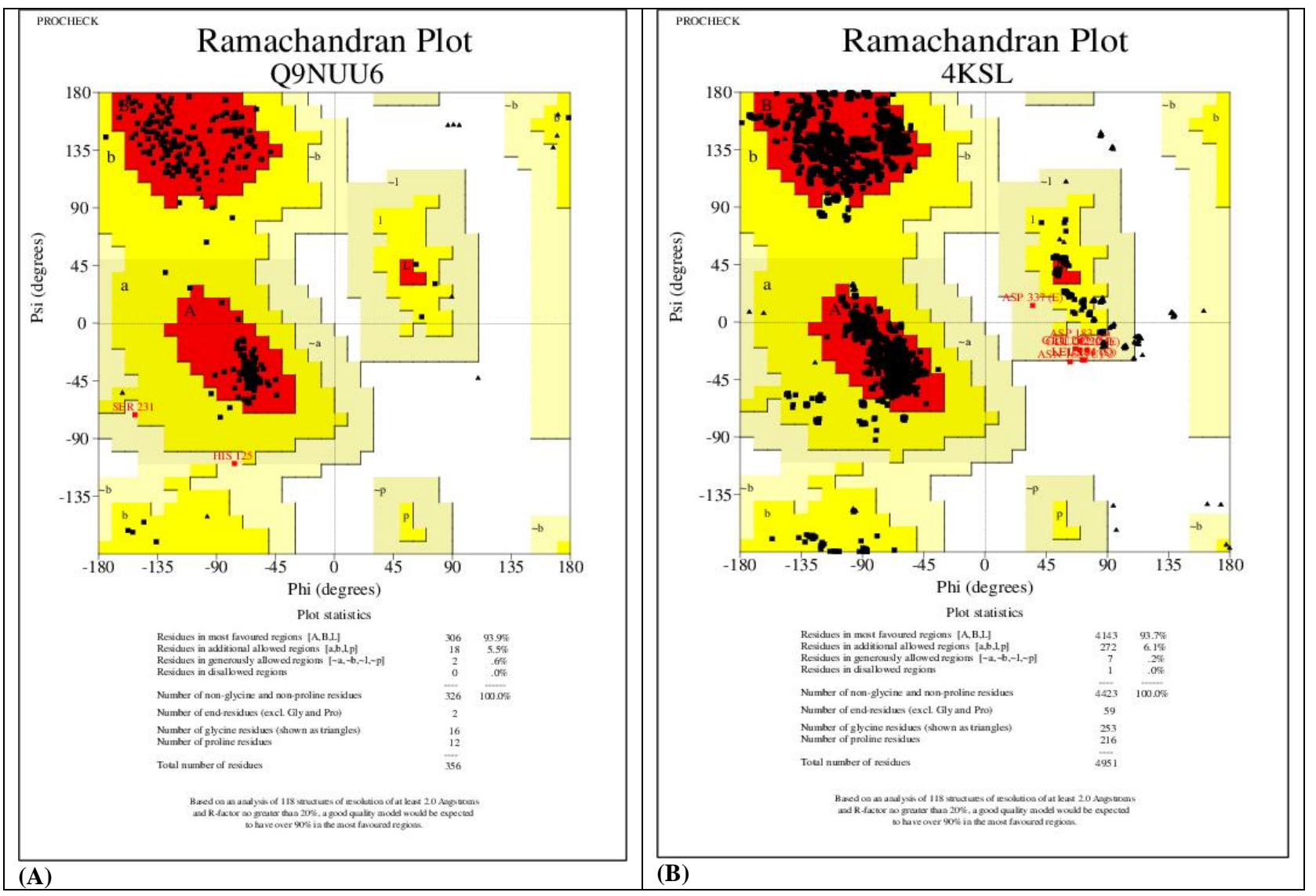

FIG. 1: RAMACHANDRAN PLOT ANALYSIS OF THE BACKBONE DIHEDRAL ANGLES PSI ( $\Psi)$ AND PHI ( () OF (A) THE GENERATED MODEL AND (B) THE TEMPLATE MODEL 4KSL CHAIN A.

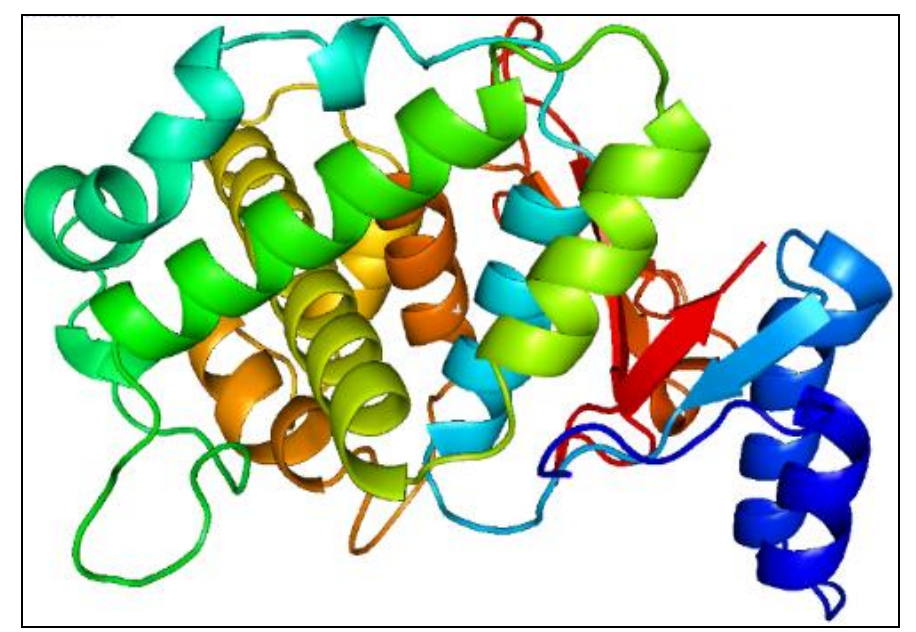

FIG. 2: SECONDARY STRUCTURE OF THE PREDICTED MODEL

\section{Molecular docking Results:}

Molecular docking is the most widely used method for the calculation of protein-ligand interactions. Docking is a most efficient technique to predict thepotential ligand binding sites on the whole protein. To explore the predictability as well as the characteristics of the binding pocket of the modelled model and to make the rational design of novel and more selective antagonists of Inactive ubiquitin thioesterase FAM105A. Molecular 
docking was carried out on developed Inactive ubiquitin thioesterase FAM105A binding pocket using a set of Inactive ubiquitin thioesterase FAM105A antagonists shown in Table 1. The 10 docking conformations for each molecule were generated. Autodock4.2 also uses free energy binding assessment to assign the best binding conformation. Energies estimated by Autodock are described by intermolecular energy (including Vander Waals, hydrogen bonding, and electrostatic energies), internal energy, and torsional free energy.

The hydrogen bond interaction and electrostatic interaction between the receptor and ligand is the most important, because it can allocate the strength of binding and the exact position of the ligand in the active site. Structures of molecules are given in Table 1.

\section{TABLE 1: SYNTHESIZED BENZIMIDAZOLE DERIVATIVES USED FOR MOLECULAR DOCKING}

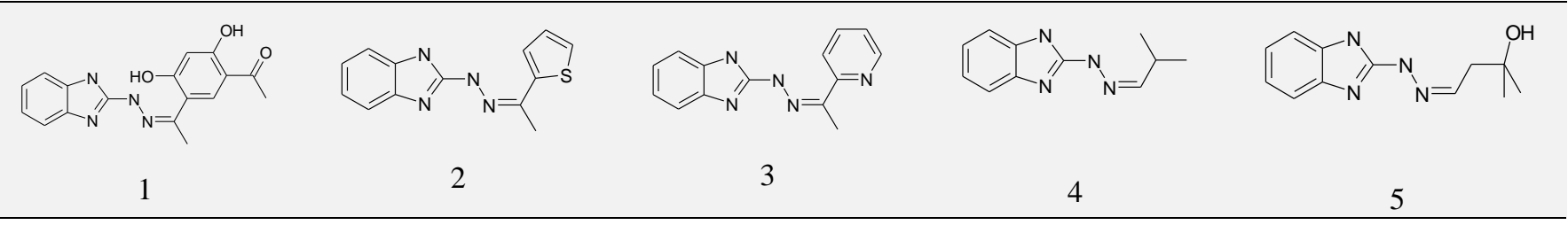

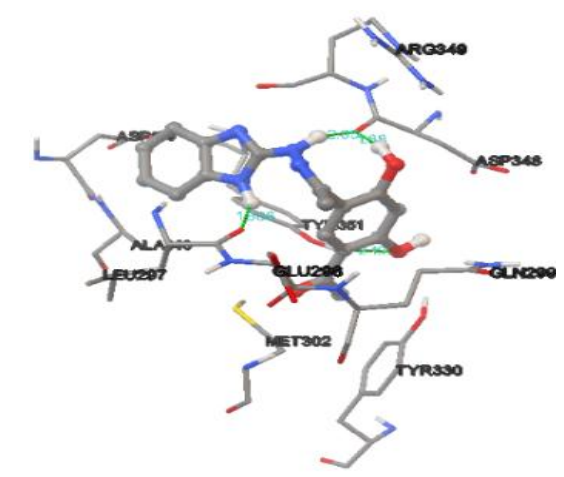

1

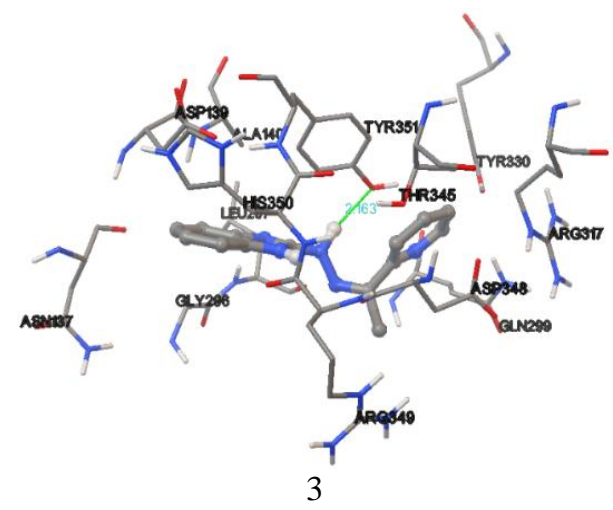

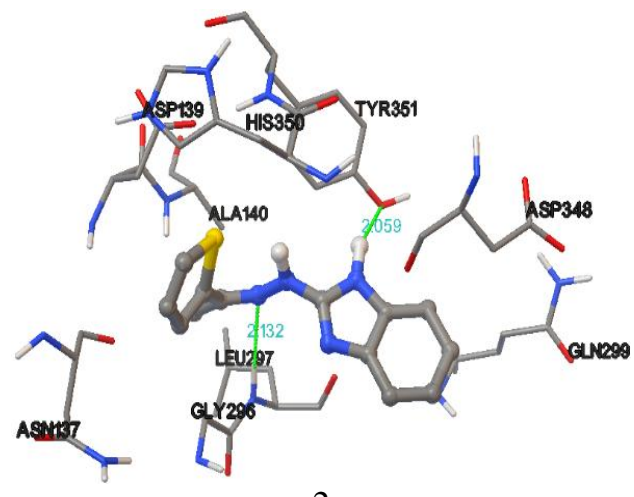

2

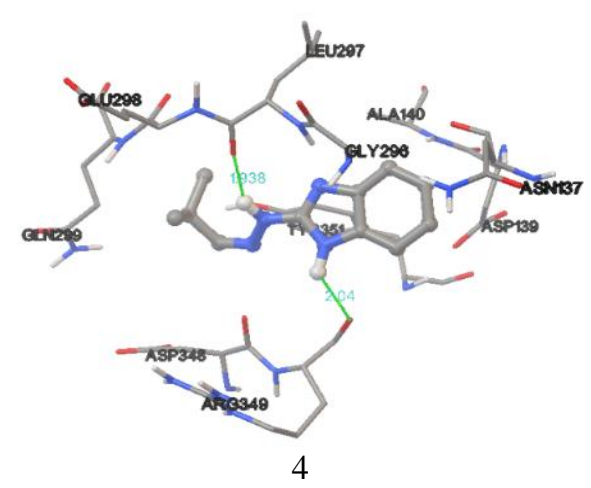

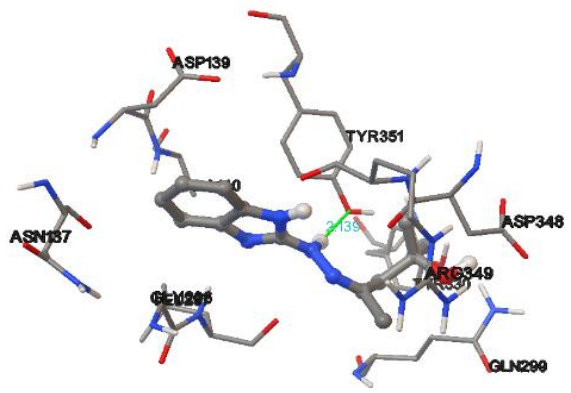

5

FIG. 3: DOCKING POSE OF THE COMPOUNDS 1-5 IN THE ACTIVE SITE OF INACTIVE UBIQUITIN THIOESTERASE FAM105A 
Molecular docking studies were carried out for five synthesized Benzimidazole derivatives against Inactive ubiquitin thioesterase FAM105A. The binding energy, inhibition constant, hydrogen bond forming residues and interacting residues of all the five synthesized derivatives when docked with Inactive ubiquitin thioesterase FAM105A is as given in Table 2 . The binding energy for all the molecules range from -5.17 to $-7.34 \mathrm{kcal} / \mathrm{mol}$. Compound Three having highest binding energy of
$-7.34 \mathrm{kcal} / \mathrm{mol}$. This compound had shown only one interaction with Tyr351 as shown in Fig. 3 thus indicating that Inactive ubiquitin thioesterase FAM105A has lowest affinity towards compound three. Compound one shows three interactions and compound two and four interacts with Leu297 and Tyr351 and Leu297 and Arg349 respectively. Compound 3 and compound 5 interacts with Tyr351.

\begin{tabular}{|c|c|c|c|c|}
\hline S. No & Interacting amino acids & Grid $X-Y-Z$ coordinates & $\begin{array}{c}\text { Binding energy } \\
\Delta \mathrm{G} \\
\text { (Kcal/Mol) } \\
\end{array}$ & $\begin{array}{l}\text { Dissociation } \\
\text { constant (kI) }\end{array}$ \\
\hline 1 & Asp348, Leu297, Tyr351 & $-42.267,33.699,-12.982$ & -5.17 & $163.31 \mu \mathrm{M}$ \\
\hline 2 & Leu297, Tyr351 & $-42.267,33.699,-12.982$ & -6.84 & $9.63 \mu \mathrm{M}$ \\
\hline 3 & Tyr351 & $-42.267,33.699,-12.982$ & -7.34 & $4.17 \mu \mathrm{M}$ \\
\hline
\end{tabular}

\section{CONCLUSION: We had synthesized}

Benzimidazole derivatives in present study and evaluated for ubiquitone inhibition. The 3D structure of Q9NUU6 of Human was generated using Modeller 9.15. The generated model assessment was revealed that the model is reliable and a quality model with stable energies. Additionally the molecular docking studies were performed to all the compounds into the binding cavity of Q9NUU6, which showed favourable interactions with all the compounds. Third compound shows highest binding energy of -7.34 $\mathrm{kcal} / \mathrm{mol}$. except fourth compound all the other compounds shows two interactions. Hence we conclude that all these synthesized compounds could be a potential lead molecules for inhibiting ubiquitin thioesterase.

\section{REFERENCES:}

1. Burger A. M, Seth AK. The ubiquitin-mediated protein degradation pathway in cancer: therapeutic implications. Eur. J. Cancer 2004; 40: 2217-2229.

2. Lake MW, Wuebbens MM, Rajagopalan KV, Schindelin H. Mechanism of ubiquitin activation revealed by the structure of a bacterial MoeB-MoaD complex. Nature 2001, 414, 325-329.

3. Kerscher O, Felberbaum R, Hochstrasser M. Modification of proteins by ubiquitin and ubiquitin-like proteins. Annu Rev Cell Dev Biol. 2006, 22, 159-180.

4. Zhu Y, Li H, Hu L, Wang J, Zhou Y, Pang Z, Liu L, Shao F. Structure of a Shigella effector reveals a new class of ubiquitin ligases. Nat StructMol Biol. 2008, 15(12), 13021308 .
5. Taha, M.; Ismail, N. H.; Imran, S.; Selvaraj, M.; Rashwan, H.; Farhanah, F. U.;Rahim, F.; Selvarajan, K. K.; Ali, Synthesis of benzimidazole derivatives as potent $\beta$ glucuronidase inhibitors M. Bioorg. Chem.2015, 61, 36.

6. Abdullah, N. K. N. Z.; Taha, M.; Ahmat, N.; Wadood, A.; Ismail, N. H.; Rahim, F.; Ali, M.; Abdullah, N. Novel 2, 5disubtituted-1, 3, 4-oxadiazoles with benzimidazole backbone: a new class of $\beta$-glucuronidase inhibitors and in silico studies. M. Bioorg. Med. Chem.2015, 23, 3119.

7. Saify, Z. S.; Kamil, A.; Akhtar, S.; Taha, M.; Khan, A.; Khan, K. M.; Jahan, S.; Rahim, F.; Perveen, S.; Choudhary, 2-(2'-Pyridyl) benzimidazole derivatives and their urease inhibitory activity M. I.Med. Chem. Res.2014, 23, 4447.

8. Khan, K. M.; Khan, M.; Saleem, M.; Taha, M.; Perveen, S.; Choudhary, M. I. Benzimidazoles: a new class of carbonic anhydrase inhibitors. J. Pak.Chem Soc.2013, 35, 901.

9. Wank SA. G protein-coupled receptors in gastrointestinal physiology. I. CCK receptors: an exemplary family. American Journal of Physiology -Gastrointestinal and Liver Physiology. 1998, 274(4): G607-G613.

10. Kumara D, Jacobb MR, Reynoldsa MB, Sean M, Kerwin SM. Synthesis and evaluation of anticancer benzoxazoles and benzimidazoles related to UK-1. Bioorg Med Chem. 2002, 10:3997-4004.

11. Tiwari AK, Mishrab AK, Bajpai A, Mishra P, Singh S, Sinha D, Singh VK. Synthesis and evaluation of novel benzimidazole derivative [Bz-Im] and its radio/biological studies. Bioorg Med Chem Lett. 2007, 17: 2749-2755.

12. Arjmand F, Mohani B, Ahmad S. Synthesis, antibacterial, antifungal activity and interaction of CTDNA with a new benzimidazole derived $\mathrm{Cu}$ (II) complex. Eur J Med Chem. 2005, 40: 1103-1110.

13. Achar KCS, Hosamani KM, Seetharamareddy HR. In-vivo analgesic and anti-inflammatory activities of newly synthesized benzimidazole derivatives. Eur J Med Chem. 2010, 45:2048-2054.

14. Kuhler TC, Swanson M, Shcherbuchin V, Larsson H, Mellgard B, Sjostrom JE. Structure-activity relationship 
of 2-[[(2-pyridyl)-methyl]thio]-1Hbenzimidazoles as anti Helicobacter pylori agents in vitro and evaluation of their in vivo efficacy. J Med Chem. 1998, 41:17771788.

15. Horn J. The Proton-pump inhibitors: similarities and differences. ClinTher. 2000, 22:266-280.

16. Sondhi, S. M.; Bhattacharjee, G.; Jameel, R. K.; Shukla, R.; Raghubir, R.; Lozach,O.; Meijer, L.Cent. Antiinflammatory, analgesic and kinase inhibition activities of some acridine derivatives. Eur. J. Chem.2004, 2,1 .

17. Garuti, L.; Roberti, M.; Pizzirani, D.; Pession, A.; Leoncini, E.; Cenci, V.; Hrelia, S. Differential antiproliferative activity of new benzimidazole-4, 7diones.IlFarmaco 2004, 59, 663.

18. Kumar, D.; Jacob, M. R.; Reynolds, M. B.; Kerwin, S. M. Synthesis and evaluation of anticancer benzoxazoles and benzimidazoles related to UK-1.Bioorg. Med. Chem.2002, 10, 3997.

19. Paramashivappa, R.; Phani Kumar, P.; Subba Rao, P. V.; Srinivasa, R. A. Design, synthesis and biological evaluation of benzimidazole/ benzothiazole and benzoxazole derivatives as cyclooxygenase inhibitors. Bioorg.Med. Chem. Lett.2003, 13, 657.

20. Ozkay, Y.; Tanah, Y.; Karaka, H.; Iskdag, I. Antimicrobial activity and a SAR study of some novel benzimidazole derivatives bearing hydrazone moiety. Eur. J. Med. Chem.2010, 45, 3293.

21. Grimmett M. Comprehensive heterocyclic chemistry: the structure, reactions, synthesis and uses of heterocyclic compounds, vol 3. Pergamon, Oxford. 1996, p 77.

22. Orjales A, Mosquera R, Labeaga L, Rodes R. New 2piperazinyl benzimidazole derivatives as 5-HT3 antagonists. Synthesis and pharmacological evaluation. J Med Chem. 1997, 40:586-593.

23. Gasteiger E, Gattiker A, Hoogland C, Ivanyi I, Appel RD, Bairoch A., ExPASy: theproteomics server for in-depth protein knowledge and analysis. Nucleic Acids Res. 2003, 31(13), 3784-3788.

24. Altschul SF, Madden TL, Schäffer AA, Zhang J, Zhang Z, Miller W, Lipman DJ. Gapped BLAST and PSI-BLAST: a new generation of protein database search programs. Nucleic Acids Res. 1997, 25(17), 3389-3402.

25. Gunda SK, Chary Rudroju S, Bandi S and Bodhankar R. Homology modeling of human asparaginase like protein and its molecular interaction studies with natural flavonoids. Int J Pharm Sci Res.2016, 7(1), 287-291.

26. Gunda SK, Adi Mahalakshmi $M$ and Mahmood S. Molecular Modelling and Docking Studies of Human Blood Coagulation Factor-XIIIA Protein. International Journal of Research in Pharmaceutical and Biomedical Sciences. 2013, 4, 647-655.

27. Sali A, Blundell TL. Comparative Protein modelling by satisfaction of spatial restraints. J Mol Biol. 1993, 234, 779-815.

28. Ramachandran GN, Ramakrishnan C, Sasisekharan V. Stereochemistry of polypeptide chain configurations. J Mol. Biol. 1963, 7, 95-99.

29. Shahlaei M, Madadkar-Sobhani A, Mahnam K, Fassihi A, Saghaie L, Mansourian M. Homology modeling of human CCR5 and analysis of its binding properties through molecular docking and molecular dynamics simulation. BiochimBiophysActa. 2011, 1808(3), 802-817.

30. Ranjithreddy P, Mohmed J, Reshma P, Gunda SK. 2,6disubstituted-4,5,6,7-tetrahydrothieno[2,3-c]pyridine-3carboxamide derivatives as anti-mycobacterial agents: a 3D QSAR approach. Int J Pharm 2015, 5(3), 867-874.

How to cite this article:

Neelamma M and Chitluri KK: Comparative Modeling of Inactive Ubiquitin Thioesterase Fam105a and Molecular Docking Studies of Synthesized Benzimidazole Derivatives. Int J Pharm Sci Res 2016; 7(10): 4085-90.doi: 10.13040/IJPSR.0975-8232.7(10).4085-90.

All @ 2013 are reserved by International Journal of Pharmaceutical Sciences and Research. This Journal licensed under a Creative Commons Attribution-NonCommercial-ShareAlike 3.0 Unported License.

This article can be downloaded to ANDROID OS based mobile. Scan QR Code using Code/Bar Scanner from your mobile. (Scanners are available on Google Playstore) 